\title{
GAMBARAN EFEK SAMPING PADA AKSEPTOR KB PENGGUNA METODE OPERATIF PRIA (MOP) DI KECAMATAN SINGAPARNA KABUPATEN TASIKMALAYA TAHUN 2016
}

Oleh :

Happi Apriasih, SST, M.Kes

\section{A. Abstrak}

Vasektomi adalah metode kontrasepsi yang dilakukan dengan memotong saluran sperma (vas deferens) yang membawa sperma dari testis ke penis. Dengan metode yang menyerupai sterilisasi ini, sperma tidak lagi keluar bersama air mani saat pria ejakulasi atau dikenal dengan nama MOP (Metode Operatif Pria). Berdasarkan data di Puskesmas Singaparna bahwa cakupan penggunaan MOP paling rendah dibandingkan dengan metode kontrasepsi lain, banyak faktor yang mempengaruhi diantaranya adalah resiko efek samping meskipun tergolong rendah.Tujuan penelitian ini adalah mengetahui gambaran efek samping metode kontrasepsi MOP di Kec Singaparna Kab Tasikmalaya Tahun 2016.

Metode penelitian yang digunakan adalah kuantitatif, jenis penelitian deskriptif. Pengumpuan data yang digunakan adalah data primer dengan instrumen penelitian kuesioner. Sampel terdiri dari 8 orang akseptor KB MOP. Analisis data yang digunakan adalah univariat.

Hasil penelitian dapat diketahui bahwa $100 \%$ responden MOP tidak mengalami efek samping baik efek samping mayor atau efek samping minor, meskipun ada faktor lainnya yang dirasakan pada satu orang pengguna MOP yaitu penurunan libido tetapi bukan faktor utama karena dilihat dari faktor lain seperti pengaruh pekerjaan dan usia.

Kesimpulan penelitian ini adalah seluruh akseptor pengguna MOP tidak mengalami efek samping minor dan mayor. Saran penelitian ini adalah meningkatkan KIE dan konseling KB PUS dan menggalakan kembali safari KB atau pelayanan KB gratis.

\section{Kata Kunci: Efek samping, Metode Kontrasepsi MOP}




\section{B. Latar Belakang}

Indonesia saat ini dihadapkan pada masalah kependudukan yang semakin lama semakin meningkat jumlahnya, dengan laju pertumbuhan penduduk 1,2 $\%$ pertahun sedangkan target kurang dari $1 \%$ pertahun, oleh karena itu pemerintah terus berupaya untuk dapat menekan laju pertumbuhan penduduk melalui Program BKKBN yang didalamnya terdapat ruang lingkup pelayanan kontrasepsi, dengan penggunaan kontrasepsi diharapkan dapat mengurangi jumlah penduduk setiap tahunnya karena salah satu kualitas negara dilihat dari jumlah penduduknya. (Depkes RI, 2005).

Berbagai metode kontrasepsi berkembang di Indonesia salah satu nya adalah metode KB Kontrasepsi Pria yaitu yang dikenal dengan Vasektomi atau Metode Operatif Pria, meskipun berdasarkan data Sejauh ini penggunaan alat kontrasepsi pria di Indonesia masih sangat rendah karena berdasarkan catatan BKKBN, persentase penggunaan alat kontrasepsi pria baru sekitar 3,5 persen, sebagian di antaranya berupa vasektomi.

Vasektomi adalah metode kontrasepsi yang dilakukan dengan memotong saluran sperma (vas deferens) yang membawa sperma dari testis ke penis. Dengan metode yang menyerupai sterilisasi ini,_sperma tidak lagi keluar bersama air mani saat pria ejakulasi. Di kalangan awam, metode vasektomi memang banyak yang mempertanyakan. Salah satunya mitos bahwa vasektomi dapat memengaruhi gairah seksual pria. Padahal, tidak demikian. Setelah vasektomi, seorang pria tetap akan merasakan sensasi orgasme, ereksi bahkan ejakulasi. Memang, sesaat setelah vasektomi dilakukan, ada kasus yang mengalami rasa nyeri di bagian testis, tetapi hal itu hanya sementara. Beberapa hari setelah prosedur vasektomi, seorang pria dapat segera melakukan hubungan seksual.
Vasektomi juga tidak akan memengaruhi produksi hormon testosteron pada pria. Demikian juga air mani yang keluar saat ejakulasi setelah vasektomi, tidak akan banyak berbeda, karena sperma hanya merupakan bagian kecil dari air mani secara keseluruhan.

Sebagai metode kontrasepsi permanen, vasektomi memiliki keunggulan sebagai prosedur yang aman dan minim komplikasi serta murah karena hanya dilakukan satu kali seumur hidup. Hanya saja vasektomi tidak melindungi pria dari infeksi menular seksual, sehingga diperlukan alat kontrasepsi lain seperti kondom, untuk hal tersebut.

Meski tergolong rendah, ada beberapa risiko komplikasi dari vasektomi yaitu Hematoma yaitu pendarahan di bawah kulit yang dapat menyebabkan pembengkakan yang terasa sakit. Infeksi yang dapat diiringi dengan demam atau kemerahan pada kantong pelir (skrotum). Rasa nyeri pada testis yang tidak segera menghilang yaitu postvasectomy pain syndrome. Benjolan pada skrotum atau disebut juga granuloma yaitu sperma yang keluar dari saluran sperma ke dalam jaringan. Peradangan pada saluran sperma atau epididimitis kongestif.Kegagalan vasektomi. Memang tergolong kecil yaitu sekitar 11 dari 1.000 vasektomi pada dua tahun pertama.

Berdasarkan rekomendasi Konperensi Internasional Kependudukan dan Pembangunan (ICPD, 1994, di Kairo), dan Convention on the Elimination of all Forms of Discrimination Againts Women (CEDAW), Indonesia telah mulai melaksanakan pembangunan yang berorientasi pada keadilan dan kesetaraan gender dalam keluarga berencana dan kesehatan reproduksi., maka banyak tantangan di masa yang akan datang, berbagai upaya harus dilakukan untuk meningkatkan partisipasi pria dalam keluarga 
berencana dan kesehatan reproduksi dan telah menjadi salah satu strategi utama dalam pelaksanaan program $\mathrm{KB}$ nasional.

Berdasarkan data di Puskesmas Singaparna bahwa cakupan penggunaan MOP paling rendah dibandingkan dengan metode kontrasepsi lain, data pencapaian peserta KB Aktif di Kecamatan Singaparna menunjukkan bahwa tahun 2014 dari 13.725 PUS hanya $10(0,0007 \%)$ orang , 11 $(0,001 \%)$ orang dari 10.489 PUS di tahun 2015 dan $10(0,0009 \%)$ orang dari 10.559 PUS di tahun 2016

\section{Metode}

\section{Jenis Penelitian}

Penelitian ini merupakan penelitian kuantitatif dengan metode deskriptif, yang bertujuan untuk mengambarkan efek samping penggunaan metode kontrasepsi MOP di Kec Singaparna Kab Tasikmalaya Tahun 2016.

\section{Populasi dan Sampel}

Populasi penelitian adalah seluruh suami/Pria akseptor KB yang menggunakan kontrasepsi MOP, dengan pengambilan sampel menggunakan teknik total sampling dengan sampel 8 orang pengguna MOP di Tahun 2016 periode Januari sampai dengan Juli 2016.

\section{Tempat dan waktu}

Penelitian ini dilaksanakan di Kecamatan Singaparna pada Bulan April- Juli 2016.

\section{Variabel Penelitian}

Penelitian ini menggunakan satu variabel yaitu gambaran efek samping akseptor $\mathrm{KB}$ terhadap penggunaan kontrasepsi jangka panjang.

\section{Prosedur Pengambilan data}

\section{a. Data Primer}

Pengumpulan data primer dilakukan dengan menggunakan angket, yaitu menyebarkan kuisioner kepada responden yang tercatat di Kecamatan Singaparna. Pengisian kuesioner diisi langsung oleh responden, dengan pengguna MOP dan tidak sedikit rumor yang salah terkait dengan metode KB MOP, oleh karena itu maka penulis bermaksud untuk melakukan penelitian yang berjudul "Gambaran Efek Samping Pada Akseptor KB Pengguna Metode Operatif Pria (MOP) di Kecamatan Singaparna Kabupaten Tasikmalaya tahun 2016'.

Penelitian ini bertujuan untuk mengetahui Gambaran Efek Samping Pada Akseptor KB Pengguna Metode Operatif Pria (MOP) di Kecamatan Singaparna Kabupaten Tasikmalaya tahun 2016.

pengawasan langsung oleh peneliti beserta kader, Proses pengambilan data berlangsung kurang lebih 1 bulan, dari rencana total responden 10 orang 2 orang meninggal dunia sehingga total yang didapatkan 8 orang responden.

\section{b. Data Sekunder}

Pengambilan data sekunder diperoleh dari catatan yang sudah tersedia dalam profil kesehatan DTP Puskesmas Singaparna dan cakupan akseptor KB di kecamatan singaparn tahun 2015

\section{Instrumen Penelitian}

Instrumen yang digunakan adalah kuesioner berupa angket yang diisi langsung oleh responden. Daftar pertanyaan disusun berdasarkan pedoman kaidah ilmu kebidanan. Jumlah soal terdiri dari pertanyaan tertutup dan terbuka mengenai umur, jumlah anak, pendidikan ibu, pekerjaan ibu, penggunaan metode $\mathrm{KB}$, lama penggunaan dan efek samping yang dirasakan selama penggunaan KB tersebut meliputi efek samping penggunaan MOP dilihat dari efek samping minor yaitu ecchimosis , pembengkakan dan rasa sakit serta efek samping mayor yaitu hematoma, infeksi, sperm granuloma.

\section{Analisis Data}

Analsis data yang digunakan adalah analisis unvariat. Analisa univariat dilakukan untuk melihat distribusi 
frekuensi dari variabel dependen. Dibuat tabel istribusi frekuensi dari semua sebaran variabel yang terdapat dalam penelitian ini. Analisa univariat dilakukan dengan menggunakan rumus distribusi frekuensi.

\section{Hasil penelitian}

1. Umur Responden

Tabel 5.1 Distribusi Frekuensi Umur Responden yang menggunakan MOP di Kecamatan Singaparna Kabupaten Tasikmalaya Tahun 2016

\begin{tabular}{|c|c|c|c|}
\hline No & \multicolumn{1}{|c|}{ Umur Responden } & Frekuensi & Persentase (\%) \\
\hline 1 & $<35$ & 0 & 0 \\
\hline 2 & $>35$ tahun & 8 & 100 \\
\hline \multicolumn{2}{|c|}{ Jumlah } & $\mathbf{8}$ & $\mathbf{1 0 0}$ \\
\hline
\end{tabular}

Tabel diatas menunjukkan bahwa sebagian besar responden yang menggunakan MOP adalah $>35$ tahun yaitu $100 \%$

2. Pendidikan Responden

Tabel 5.2 Distribusi Frekuensi Pendidikan Responden yang menggunakan MOP di

Kecamatan Singaparna Kabupaten Tasikmalaya Tahun 2016

\begin{tabular}{|c|l|c|c|}
\hline No & Pendidikan Responden & Frekuensi & Persentase (\%) \\
\hline 1 & SD & 4 & 50 \\
\hline 2 & SMP & 1 & 12,5 \\
\hline 3 & SMA & 2 & 25 \\
\hline 4 & PT Jumlah & 1 & 12,5 \\
\hline \multicolumn{2}{|c|}{$\mathbf{8}$} & $\mathbf{1 0 0}$ \\
\hline
\end{tabular}

Tabel diatas menunjukkan bahwa sebagian besar pendidikan responden yang menggunakan MOP adalah SD yaitu $50 \%$.

\section{Jumlah Anak}

Tabel 5.3 Distribusi Frekuensi Jumlah Anak Responden yang menggunakan MOP di

Kecamatan Singaparna Kabupaten Tasikmalaya Tahun 2016

\begin{tabular}{|c|c|c|c|}
\hline No & Jumlah Anak & Frekuensi & Persentase (\%) \\
\hline 1 & $>2$ & 8 & 100 \\
\hline \multicolumn{2}{|c|}{} & $\mathbf{8}$ & $\mathbf{1 0 0}$ \\
\hline
\end{tabular}

Tabel diatas menunjukkan seluruh rsponden yang menggunakan MOP telah memiliki anak lebih dari 2 .

\section{Pekerjaan Responden}

Tabel 5.4 Distribusi Frekuensi Pekerjaan Responden yang menggunakan MOP di Kecamatan Singaparna Kabupaten Tasikmalaya Tahun 2016

\begin{tabular}{|c|l|c|c|}
\hline No & \multicolumn{1}{|c|}{ Pekerjaan Responden } & Frekuensi & Persentase (\%) \\
\hline 1 & PNS & 3 & 37,5 \\
\hline 2 & BURUH & 2 & 25 \\
\hline 3 & WIRASWASTA & 3 & 37,5 \\
\hline \multicolumn{2}{|c|}{ Jumlah } & $\mathbf{8}$ & $\mathbf{1 0 0}$ \\
\hline
\end{tabular}

Tabel diatas menunjukkan bahwa pekerjaan responden rata-rata bekerja sebagai PNS $(37, \%)$ dan wiraswasta $(37, \%)$ hanya sebagian kecil responden yang menjadi buruh $(25$ $\%)$. 


\section{Riwayat Kesehatan Istri}

Tabel 5.5 Distribusi Frekuensi Riwayat Kesehatan Istri yang menggunakan MOP di Kecamatan Singaparna Kabupaten Tasikmalaya Tahun 2016

\begin{tabular}{|c|l|c|c|}
\hline No & Riwayat Kesehatan istri & Frekuensi & Persentase (\%) \\
\hline 1 & Mempunyai Riwayat Penyakit & 5 & 62,5 \\
\hline 2 & Tidak Mempunyai Riwayat Penyakit & 3 & 37,5 \\
\hline \multicolumn{2}{|c|}{ Jumlah } & $\mathbf{8}$ & $\mathbf{1 0 0}$ \\
\hline
\end{tabular}

Tabel diatas menunjukkan bahwa sebagian besar istri responden pengguna MOP mempunyai riwayat penyakit diantaranya tekanan darah tinggi, tumor saluran kencing dan sesak napas .

6. Riwayat alat kontrasepsi yang dipakai istri

Tabel 5.6 Distribusi Frekuensi Alat Kontrasepsi yang dipakai istri responden yang menggunakan MOP di Kecamatan Singaparna Kabupaten Tasikmalaya Tahun 2016

\begin{tabular}{|c|l|c|c|}
\hline No & Riwayat Alat Kontrasepsi & Frekuensi & Persentase (\%) \\
\hline 1 & Pernah menggunakan & 3 & 37,5 \\
\hline 2 & Tidak Pernah Menggunakan & 5 & 62,5 \\
\hline \multicolumn{2}{|c|}{ Jumlah } & $\mathbf{8}$ & $\mathbf{1 0 0}$ \\
\hline
\end{tabular}

Tabel diatas menunjukkan bahwa sebagian besar istri responden pengguna MOP tidak pernah menggunakan alat kontrasepsi yaitu $62,5 \%$ dan $37,5 \%$ diantaranya pernah menggunakn kontrasepsi IUD, Pil, Suntik namun tidak cocok.

\section{Penghasilan Suami}

Tabel 5.7 Distribusi Frekuensi Penghasilan Responden yang menggunakan MOP di Kecamatan Singaparna Kabupaten Tasikmalaya Tahun 2016

\begin{tabular}{|c|c|c|c|}
\hline No & Penghasilan Responden & Frekuensi & Persentase (\%) \\
\hline 1 & $>$ UMR & 5 & 62,5 \\
\hline 2 & <UMR Jumlah & 3 & 37,5 \\
\hline \multicolumn{2}{|c|}{ Jur| } & $\mathbf{8}$ & $\mathbf{1 0 0}$ \\
\hline
\end{tabular}

Tabel diatas menunjukkan bahwa sebagian besar responden mempunyai penghasilan lebih dari UMR (62,5\%).

8. Tempat Pelayanan

Tabel 5.8 Distribusi Frekuensi Tempat Pelayanan responden pengguna MOP di Kecamatan Singaparna Kabupaten Tasikmalaya Tahun 2016

\begin{tabular}{|c|c|c|c|}
\hline No & Tempat Pelayanan & Frekuensi & Persentase (\%) \\
\hline 1 & RS & 3 & 37,5 \\
\hline 2 & Lain-lain & 5 & 62,5 \\
\hline & Jumlah & 8 & 100 \\
\hline
\end{tabular}

Tabel diatas menunjukkan bahwa tempat pelayanan MOP sebagian kecil di Rumah Sakit $(37,5 \%)$ dan sebagian besar di tempat pelayanan Safari KB.

\section{Efek Samping}

a. Efek Samping Minor

Tabel 5.9.1 Distribusi Frekuensi Efek Samping Minor pada responden pengguna MOP di Kecamatan Singaparna Kabupaten Tasikmalaya Tahun 2016

\begin{tabular}{|c|c|c|c|}
\hline No & Efek Samping Minor & Frekuensi & Persentase (\%) \\
\hline 1. & Tidak & 8 & 100 \\
\hline \multicolumn{2}{|c|}{ Jumlah } & $\mathbf{8}$ & $\mathbf{1 0 0}$ \\
\hline
\end{tabular}


Tabel diatas menunjukkan bahwa seluruh responden tidak mempunyai efek samping minor pada penggunaan MOP.

b. Efek Samping Mayor

Tabel 5.9.2 Distribusi Frekuensi Efek Samping Mayor pada responden pengguna MOP di Kecamatan Singaparna Kabupaten Tasikmalaya Tahun 2016

\begin{tabular}{|c|c|c|c|}
\hline No & Efek Samping Mayor & Frekuensi & Persentase (\%) \\
\hline 1. & Tidak & 8 & 100 \\
\hline \multicolumn{2}{|c|}{ Jumlah } & $\mathbf{8}$ & $\mathbf{1 0 0}$ \\
\hline
\end{tabular}

Tabel diatas menunjukkan bahwa seluruh responden tidak mempunyai efek samping minor pada penggunaan MOP.

c. Efek Samping Lain

Tabel 5.9.3 Distribusi Frekuensi Efek Samping Lain pada responden pengguna MOP di Kecamatan Singaparna Kabupaten Tasikmalaya Tahun 2016

\begin{tabular}{|c|lc|c|c|}
\hline No & Efek Samping & Frekuensi & Persentase (\%) \\
\hline 1 & Ya & 1 & 12,5 \\
\hline 2 & Tidak & 7 & 87,5 \\
\hline \multicolumn{2}{|c|}{} & Jumlah & $\mathbf{8}$ & $\mathbf{1 0 0}$ \\
\hline
\end{tabular}

Tabel diatas menunjukkan bahwa sebagian besar responden $(87,5 \%)$ pengguna tidak merasakan efek samping lain, hanya 1 orang yang merasakan penurunan libido.

\section{E. Pembahasan}

Berdasarkan hasil penelitan didapatkan bahwa seluruh responden pengguna metode kontrasepsi MOP (Metode Operatif Pria) atau yang dikenal dengan Vasektomi tidak mengalami keluhan atau efek samping pasca pemasangan baik efek samping minor seperti adanya perubahan warna kulit kemerahan akibat memar setelah dilakukannya operasi, pembengkakan, dan adanya rasa nyeri maupun efek samping mayor seperti hematoma atau pembengkakan beberapa hari setelah operasi, adanya infeksi berupa nanah dan rasa sakit yang tiba-tiba dan pembengkakan pada lokasi operasi setelah 1-2 minggu, sedang sebelumnya sama sekali tanpa adanya gejala, hal tersebut menunjukan bahwa ternyata tidak ada efek samping terjadi pada ke 8 responden pengguna MOP kemungkinan didukung oleh perawatan pasca operasi yang baik sehingga tidak muncul efek samping maupun komplikasi, dan juga didukung oleh pola hidup responden yang baik diihat dari penghasilan yang baik sehingga kemungkinan pola nutrisi pun baik karena untuk mempercepat penyembuhan bisa dipengaruhi oleh salah satunya pola nutrisi yang baik sejalan dengan penelitian yang telah dilakukan oleh Herlina, dkk di RS PKU Muhammadiyah Gombong periode 2010-2011 bahwa Hasil analisa statistik dengan uji regresi linier didapatkan hasil bahwa faktor paling dominan yang mempengaruhi penyembuhan luka post operasi $S C$ di RS PKU Muhammadiyah Gombong adalah personal hygiene $(\mathrm{p}=$ $0,000)$ kemudian disusul oleh status gizi (konsumsi) dengan nilai probabilitas (Sig) 0,004.

Selain efek samping yang terjadi juga dikaji efek samping lain yang dirasakan pengguna MOP, berdasarkan hasil penelitian menunjukan bahwa sebagian besar tidak mengalami efek samping lain tetapi ada 1 responden yang mengatakan bahwa mengalami penurunan libido yaitu istilah yang 
penggunaannya secara umum berarti gairah seksual. Dalam definisi yang bersifat lebih teknis berdasarkan yang dikemukakan oleh Carl Gustav Jung, libido mempunyai pengertian sebagai energi psikis yang dimiliki individu untuk digunakan untuk perkembangan pribadi atau individuasi. Dari penelitian yang dilakukan bahwa responden yang mengalami penurunan libido mempunyai pekerjaan yang berat dimana kemungkinan besar bisa mempengaruhi terhadap kondisi stress, sejalan dengan teori (Dini A http://www.dewong.com) bahwa salah satu penyebab penurunan libido adalah berbagai kondisi medis dan kondisi fisik yang kronis dapat mengurangi gairah pada pria. Pengidap penyakit serius, seperti kanker dan depresi, tentunya dapat meredam pikiran berintim. Selain itu dilihat dari faktor usia responden yang sudah lebih dari 60 tahun dapat memicu kondisi penurunan libido sesuai dengan penelitian yang telah dilakukan oleh Claudia A. Putong, Lydia Tendean, Benny Wantouw dengan judul "Pengaruh Usia Lanjut Terhadap Hasrat Seksual Pria" di Manado RSUP Prof. Dr. R. D. Kandou Manado pada periode November 2013 hingga Januari 2014 dengan hasil penelitian menunjukkan bahwa sebanyak 57 responden dengan rentang usia 60-74 tahun melalui kuesioner ADAM dan AMS didapatkan 28 orang (49\%) gangguan orgasme ringan, 27 orang $(47,4 \%)$ penurunan frekuensi senggama sedang, 24 orang (42\%) penurunan hasrat seksual ringan dan 29 orang $(51 \%)$ gangguan ereksi ringan. Usia lanjut berpengaruh terhadap hasrat seksual pada pria. Dengan demikian dari bahasan tersebut faktor penurunan libido pada pengguna MOP bukan pengaruh langsung dari MOP tetapi ada faktor lain seperti faktor usia dan faktor pekerjaan yang dapat menyebabkan stress dan depresi.

Dilihat dari indikasi seluruh responden telah sesuai dengan indikasi penggunaan MOP dimana dari faktor jumlah anak seluruh responden sudah memenuhi persyaratan yaitu lebih dari 2 anak, dan dari usia lebih dari 35 tahun namun perlu diapresiasi adalah beberapa responden pengguna MOP memilih untuk menggunakan metode ini atas kesadaran sendiri karena tidak ada indikasi yang mengharuskan mutlak untuk menggunakan MOP seperti istri mempunyai riwayat penyakit, didukung oleh pemahaman yang baik terkait dengan MOP meskipun sebagian besar responden mempunyai pendidikan tingkat sekolah dasar tetapi jika peran petugas kesehatan nya aktif dan pihak lain seperti petugas lapangan keluarga berencana (PLKB) dapat memaksimalkan perannya dalam upaya mendukung dan menyukseskan program KB seperti kegiatan konseling terbukti dapat meningkatkan cakupan pengguna MOP, meskipun di Kecamatan Singaparna sendiri pengguna MOP terbilang masih rendah dan MOP merupakan metode yang digunakan dengan cakupan terendah dibandingkan dengan penggunaan metode kontrasepsi lainnya, hal tersebut bisa di sebabkan oleh pandangan masyarakat yang masih kurang dan kemungkinan adanya rumor yang salah terkait penggunaan MOP karena berdasarkan hasil penelitian didapatkan bahwa responden pengguna MOP sebelum menggunakan MOP pernah mendengar rumor atau mitos yang berkembang di masyarakat yaitu nafsu seksual berkurang dan menganggap bahwa ada organ reproduksi yang dibuang, oleh karena itu perlu peningkatan pengetahuan kepada masyarakat terkait dengan meluruskan kembali persepsi yang salah salah satu nya dengan peningkatan peran petugas kesehatan dan PLKB dengan KIE dan konseling akseptor KB berencana sesuai dengan dengan teori dr Hanafi Hartanto (2012 hal 27) bahwa tujuan KIE konseling adalah meningkatkan pengetahuan, sikap dan praktek KB 
sehingga tercapai penambahan akseptor baru, membina kelestarian peserta KB, meletakkan dasar bagi mekanisme sosio

\section{F. Simpulan dan saran}

\section{Simpulan}

Berdasarkan penelitian yang sudah dilakukan didapatkan bahwa tidak ada efek samping yang terjadi pada akseptor pengguna MOP baik efek samping mayor atau efek samping minor, meskipun ada faktor lainnya yang dirasakan pada satu orang pengguna MOP yaitu penurunan libido tetapi bukan faktor utama karena dilihat dari faktor lain seperti pengaruh pekerjaan dan usia.

\section{Saran}

\section{a. Tenaga Kesehatan}

Meningkatkan konseling bagi pasangan usia subur (PUS) sehingga dapat meningkatkan pemahaman PUS mengenai metode kontrasepsi MOP dan

\section{G. Referensi}

Baziad Ali, 2002. Kontrasepsi Hormonal. Jakarta. YBP Sarwono Prawirohardjo.

Claudia A. Putong, dkk, Pengaruh Usia Lanjut Terhadap Hasrat Seksual Pria Bagian Biologi dan Andrologi, Fakultas Kedokteran, UNSRAT, periode November 2013 hingga Januari 2014, Manado

Dini A, Penyebab utama hilangnya libido pada pria / https://id.wikipedia.org/wiki/Libido, diakses Agustis 2016.

Data Pencapaian Peserta KB Aktif Kecamatan Singaparna Tahun 2014, 2015, 2016.

Hartanto Hanafi. 2003.Keluarga Berencana dan Kontrasepsi. Jakarta : Pustaka Sinar harapan.

Hartanto Hanafi. 2012 .Keluarga Berencana dan Kontrasepsi. Jakarta : Pustaka Sinar harapan.

Herlina, dkk, Faktor-faktor yang mempengaruhi penyembuhan luka kultural yang dapat menjamin berlangsungnya proses penerimaan

termotivasi untuk menggunakan $\mathrm{KB}$ tersebut sehingga dapat meningkatkan partisipasi pria atau suami dalam menggunakan alat kontrasepsi

\section{b. Instansi pemerintah}

Menggalakan kembali safari KB atau pelayanan $\mathrm{KB}$ gratis terutama pelayanan KB MOP serta meningkatkan keterampilan tenaga kesehatan dan petugas lapangan keluarga berencana dalam KIE dan Konseling $\mathrm{KB}$ dan penyediaan ABPK (Alat Bantu Pengambilan keputusan) yang memadai.

\section{c. Institusi Pendidikan}

Meningkatkan anggaran dana penelitian sesuai dengan kebutuhan, serta melengkapi referensi perpustakaan sebagai upaya memperkaya khasanah ilmu pengetahuan.

post operasi SC (Sectio Caesarea) di RS PKU Muhammadiyah Gombong. periode 2010-2011.

Manuaba, Ida Bagus Gde.1998.Ilmu Kebidanan, Penyakit Kandungan, \& KB untuk Pendidikan Bidan . Jakarta : EGC.

Mardiya. 2002. Petunjuk Praktis Cara Memilih Kontrasepsi. Yogyakarta : Liberty Yogyakarta.

Meilani Niken, dkk. 2010. Pelayanan Keluarga Berencana.Yogyakarta. Fitramaya

Rencana Kerja Pemerintah (RKP) Tahun 2014

Reber, Arthur S.; Reber, Emily S. (2001). Dictionary of Psychology. New York: Penguin Reference. ISBN 0-140-51451-1. diakses Agustus 2016.

Saifuddin, Abdul bari, dkk. 2003. Buku Panduan Praktis Pelayanan Kontrasepsi. Jakarta : YBP Sarwono Prawirohardjo. 
Saifuddin, Abdul bari, dkk. 2002. Buku Acuan Nasional Pelayanan Kesehatan Maternal dan Neonatal,
Jakarta : YBP Sarwono Prawirohardjo. Wiknjosastro Hanifa, dkk. 2002 .Ilmu kebidanan. Jakarta : YBP - SP. 